\section{Effects of Stratification, Germination Temperature, and Pretreatment with Gibberellic Acid and Hydrogen Peroxide on Germination of 'Fry' Muscadine (Vitis rotundifolia) Seed}

\author{
Patrick J. Conner ${ }^{1}$ \\ Department of Horticulture, University of Georgia-Tifton Campus, 4604 \\ Research Way, Tifton, GA 31793
}

Additional index words. propagation, $\mathrm{H}_{2} \mathrm{O}_{2}$

\begin{abstract}
Germination of muscadine seed has frequently been low and irregular in the University of Georgia breeding program. A systematic study was undertaken to determine the best seed treatments and germination conditions for muscadine seed. Open-pollinated seeds of 'Fry' muscadine were used for all treatments. Stratification of seeds was performed by placing dry seed in damp vermiculite at $4{ }^{\circ} \mathrm{C}$ for periods of 0,30 , 60 , and $90 \mathrm{~d}$. The 90-d stratification period gave the highest germination percentage, with successively lower germination in the shorter stratification treatments. Pretreatment of seeds before stratification with three rates $(0.5,1.0$, and $2.0 \mathrm{M})$ of hydrogen peroxide $\left(\mathrm{H}_{2} \mathrm{O}_{2}\right)$ and four rates $\left(1,2,4\right.$, and $\left.8 \mathrm{~g} \cdot \mathrm{L}^{-1}\right)$ of gibberellic acid $\left(\mathrm{GA}_{3}\right)$ were used in an attempt to promote germination. Low rates of $\mathrm{H}_{2} \mathrm{O}_{2}(0.5 \mathrm{M})$ and $\mathrm{GA}_{3}\left(1 \mathrm{~g} \cdot \mathrm{L}^{-1}\right)$ were beneficial in some instances, whereas high rates of $\mathrm{GA}_{3}$ were detrimental. Nicking the seedcoats before stratification and soaking seeds in running water after stratification were ineffective in promoting germination. Germination temperatures of $32 / 22^{\circ} \mathrm{C}(8 \mathrm{~h} / 16 \mathrm{~h})$ were superior to $22 / 22,27 / 22$, and $37 / 22{ }^{\circ} \mathrm{C}$.
\end{abstract}

The genus Vitis contains two subgenera, Euvitis (bunch grapes) and Muscadinia (muscadine grapes). The muscadine grape, Vitis rotundifolia Michx., is the only commonly cultivated member of the Muscadinia subgenus. Muscadine grapes are native to the southern United States and have been cultivated for over 400 years. The muscadine grape differs from the familiar bunch grape (Vitis labrusca, V. vinifera, and their various hybrids) in several morphological characteristics, including that they have smaller clusters, the berries abscise from the cluster (shatter) at maturity, the tendrils are unbranched, and the berries have thick skins and a unique fruity aroma.

The University of Georgia has been breeding muscadine grapes for nearly 100 years and routinely germinates large seedling populations. In the only published study on muscadine seed germination to our knowledge, Nesbitt et al. (1976) found that germination rates in excess of $90 \%$ could be obtained by cold-stratifying seed in moist sand for 80 to $100 \mathrm{~d}$ before planting. Unfortunately, we are unable to replicate those results, and the breeding program has been hampered by erratic germination timings and low germination rates of muscadine seed.

Received for publication 13 Dec. 2007. Accepted for publication 16 Feb. 2008.

${ }^{1}$ To whom reprint requests should be addressed; e-mail pconner@uga.edu
Barriers to germination have been better studied in Euvitis grapes, and these studies provide a starting point to investigations into muscadine seed germination. Euvitis seed generally has very low germination rates until endodormancy has been removed (Ellis et al., 1983). Dormancy removal is generally achieved by cold-stratification of the seeds for a period of 3 to 4 months (Einsett and Pratt, 1975), but in many varieties, this results in only modest germination rates (Ellis et al., 1983; Scott and Ink, 1950; Selim et al., 1981). Grape seeds have a thick, tough seedcoat that can be a mechanical barrier to germination. Attempts at scarifying seeds with sulfuric acid provided minimal benefits and was harmful to seed viability if not handled carefully (ChiaWei and ShyiKuan, 2003; Scott and Ink, 1950); however, Ramirez (1968) found that nicking seeds during extraction with a blender blade was beneficial to germination. Treatment of grape seeds with gibberellic acid $\left(\mathrm{GA}_{3}\right)$ before stratification has generally been found to promote germination (Kachru et al., 1972; Pal et al., 1976; Selim et al., 1981; Yeou-Der et al., 1967). Ellis et al. (1983) found that the effect of the $\mathrm{GA}_{3}$ could be improved by an additional pretreatment in $0.5 \mathrm{M}$ hydrogen peroxide $\left(\mathrm{H}_{2} \mathrm{O}_{2}\right)$ before the $\mathrm{GA}_{3}$ pretreatment. In addition, an alternating germination temperature of $30 / 20^{\circ} \mathrm{C}$ with the higher temperature being applied for $8 \mathrm{~h}$ every $24 \mathrm{~h}$ was superior to a single germination temperature. Kachru et al. (1972) attribute grape seed dormancy to a water-soluble inhibitor, most likely abscisic acid, which can be removed with leaching by running water.

The goal of this study was to test various seed treatments in an attempt to improve overall germination rates of muscadine seed and lower the lengthy stratification periods now used.

\section{Materials and Methods}

Plant material. Open-pollinated seeds of 'Fry' muscadine were used for all treatments. Fully mature 'Fry' berries were collected from vines located at the University of Georgia-Tifton Campus. Seed was collected on 13 Sept. 2005 for Expt. 1 and Expt. 2 and on 20 Sept. 2006 for Expt. 3. Seed was extracted, washed, float-checked, and airdried for several days to $\approx 23 \%$ moisture. Dry seed was then packed in polyethylene bags and stored at $4{ }^{\circ} \mathrm{C}$ before treatment initiation.

Expt. 1: Effects of $0.5 \mathrm{M}$ hydrogen peroxide and $1 \mathrm{~g} \cdot \mathrm{L}^{-1}$ gibberellic acid pretreatment and cold-stratification period on germination rate. Seed received one of the following pretreatments before cold stratification: 1) 48-h water soak; 2) 24-h soak in $0.5 \mathrm{M}$ $\mathrm{H}_{2} \mathrm{O}_{2}$ followed by a $24-\mathrm{h}$ soak in water; 3 ) 24 -h soak in water followed by a $24-\mathrm{h}$ soak in $1 \mathrm{~g} \cdot \mathrm{L}^{-1} \mathrm{GA}_{3}$; or 4) 24-h soak in $0.5 \mathrm{M} \mathrm{H}_{2} \mathrm{O}_{2}$ followed by a 24-h soak in $1 \mathrm{~g} \cdot \mathrm{L}^{-1} \mathrm{GA}_{3}$. Pretreatments were carried out by placing 25 seeds in $10 \mathrm{~mL}$ of solution at $22^{\circ} \mathrm{C}$. After the final soak, seeds were washed three times in sterile distilled water and packed in $50 \mathrm{~mL}$ of damp sterile vermiculite and sealed in polyethylene bags. Seed was stratified at $4 \pm 2{ }^{\circ} \mathrm{C}$ in a dark refrigerator for periods of $0,30,60$, or $90 \mathrm{~d}$. Pretreatments were applied so that all stratification treatments concluded on 12 Jan. 2006. Each pretreatment $\times$ stratification period treatment was applied to four replications of 25 seeds. For germination, tests seeds were planted in $8 \times 8 \times 13$-cm pots in moist vermiculite. Pots were placed in an incubator set at an alternating cycle of $30 / 24^{\circ} \mathrm{C}$ with the higher temperature being applied for $8 \mathrm{~h}$ of each $24-\mathrm{h}$ cycle. Treatments were monitored weekly for 6 weeks for the presence of germinated seed. Seeds were considered to have germinated when the cotyledons extended above the surface of the vermiculite. At the end of the germination period, ungerminated seed was removed and tested for viability by a tetrazolium test. This was done by bisecting the seed with a knife and incubating one-half the bisected seed in a $0.5 \%$ tetrazolium chloride solution for $2 \mathrm{~h}$ at $40{ }^{\circ} \mathrm{C}$ and observing the color change.

Expt. 2: Effects of gibberellic acid, hydrogen peroxide, running water, and seedcoat nick pretreatments on germination rate. Seed received one of four rates of $\mathrm{H}_{2} \mathrm{O}_{2}(0$, $0.5,1.0$, or $2.0 \mathrm{M}$ ) or one of five rates of $\mathrm{GA}_{3}$ $\left(0,1,2,4\right.$, or $\left.8 \mathrm{~g} \cdot \mathrm{L}^{-1}\right)$ before stratification. Pretreatments were applied by soaking 25 seeds in $10 \mathrm{~mL}$ of solution for $24 \mathrm{~h}$ at $22^{\circ} \mathrm{C}$. A seedcoat nick pretreatment was applied by clipping the basal end of the seedcoat with a pair of fingernail clippers and then soaking 
the seed for $24 \mathrm{~h}$ in water before stratification. After pretreatment, seeds were stratified as described in Expt. 1 for 60 d. After stratification, a running water treatment was applied by placing seeds that had received $0 \mathrm{M} \mathrm{H}_{2} \mathrm{O}_{2}$ and $0 \mathrm{~g} \cdot \mathrm{L}^{-1} \mathrm{GA}_{3}$ pretreatments in cotton bags under a running faucet of $22^{\circ} \mathrm{C}$ water for 1,2 , 4 , or $8 \mathrm{~d}$ before planting. Each treatment was applied to four replications of 25 seeds. Seed was planted on 15 May 2006. For germination tests, seeds were treated as described in Expt. 1 except that each replication of 25 seeds was placed in a 3.8 -L pot in a greenhouse set for a minimum temperature of $21{ }^{\circ} \mathrm{C}$ and maximum temperatures were 30 to $35{ }^{\circ} \mathrm{C}$. Seed germination was recorded weekly for a period of 5 weeks.

Expt. 3: Effect of germination temperature, seed stratification period, and seed type on germination rate. Seed was pretreated by soaking seeds for $24 \mathrm{~h}$ in $0.5 \mathrm{M}$ $\mathrm{H}_{2} \mathrm{O}_{2}$ followed by a 24-h soak in $1 \mathrm{~g} \cdot \mathrm{L}^{-1}$ $\mathrm{GA}_{3}$. Seed was then cold-stratified as described in Expt. 1 for periods of 0, 30, 60, or $90 \mathrm{~d}$. The effect of seed type was investigated by taking a batch of seed at the beginning of the experiment and keeping it moist. This seed was then handled the same way as the dry seed in regard to pretreatments and subjected to a 90-d stratification period. Pretreatments were applied so that all stratification periods ended on $11 \mathrm{Jan}$. 2007. Each pretreatment $\times$ stratification period treatment was applied to four replications of 25 seeds. Each replication was planted in $8 \times 8 \times 13-\mathrm{cm}$ pots of moist vermiculite in growth chambers. Chambers were set for $8 \mathrm{~h}$ light at 22 , 27,32 , or $37^{\circ} \mathrm{C}$ followed by $16 \mathrm{~h}$ darkness at $22{ }^{\circ} \mathrm{C}$. Pots were monitored weekly for 8 weeks for the presence of germinated seed. The rate of seedling emergence was evaluated by calculating the average week of seedling emergence for all germinated seeds of a replication.

Data analysis. Final germination percentage and percentage viable seed of Expt. 1 were analyzed using a three-way analysis of variance (SigmaStat, Systat Software, San Jose, CA) with interactions tested using Fisher's least significant difference test. Percent viable seed was calculated as the number of germinated seed and the number of seed tested as viable through the tetrazolium test divided by the total number of seed in the replication. Percentage data were arsine square root-transformed for statistical analysis, but raw data are reported. Regression analysis (Minitab, State College, PA) was used to determine the best-fit relationship between $\mathrm{H}_{2} \mathrm{O}_{2}$ and $\mathrm{GA}_{3}$ concentration pretreatment and germination percentage in Expt. 2. Arsine square root transformation did not improve these relationships, so untransformed data are presented. One-way analysis of variance was used to test for differences in germination percentage between seedcoat nick and running water treatments versus the control. Percentage data were arsine square root-transformed for statistical analysis. The effect of germination temperature, stratification period, and seed type on final germination percentage and rate of seedling emergence in Expt. 3 was tested using general linear model analysis (Minitab). Germination percentage was arsine square root-transformed for statistical analysis, but raw data are reported. The data for the $0 \mathrm{~d}$ of stratification were not included in the statistical analysis of rate of seedling emergence because no seed germinated in some treatments.

\section{Results}

Stratification period had a strong effect on final germination percentage with germination rate increasing up to the maximum 90-d period (Table 1). Both the $0.5 \mathrm{M} \mathrm{H}_{2} \mathrm{O}_{2}$ and $1.0 \mathrm{~g} \cdot \mathrm{L}^{-1} \mathrm{GA}_{3}$ pretreatments increased final germination percentage. The positive effect of the pretreatments was most prominent when the seed had received less than the maximum 90-d stratification period. A combination of both pretreatments together gave superior results to either pretreatment alone. Neither pretreatment had an effect on seed viability (Table 2), but the shorter stratification periods had significantly lower seed viability. This was likely the result of the poor germination of these treatments, giving a greater chance for the seeds to rot in the germination media. Even in the highest germination treatments, final germination rates were still much lower than seed viability, indicating that dormancy had not been fully broken by any of the treatments.

In the second experiment, higher concentrations of $\mathrm{GA}_{3}$ and $\mathrm{H}_{2} \mathrm{O}_{2}$ were tested in the pretreatments to determine if further benefits could be realized. A stratification period of $60 \mathrm{~d}$ was chosen for this experiment because that period had given the largest effect with pretreatments in Expt. 1. In contrast to the first experiment, $\mathrm{H}_{2} \mathrm{O}_{2}$ pretreatment was not found to be associated with germination percentage in this experiment, although the $0.5 \mathrm{M} \mathrm{H}_{2} \mathrm{O}_{2}$ treatment had a numerically higher germination rate (data not shown).
The $\mathrm{GA}_{3}$ pretreatment was found to reduce germination (Fig. 1), although this was mostly the result of a reduction in germination at the 4 and $8 \mathrm{~g} \cdot \mathrm{L}^{-1}$ rates. Mechanically scarifiying the seedcoat by nicking the basal end of the seed did not significantly affect seed germination rate. Placing seeds in running water for 1 to $8 \mathrm{~d}$ after stratification was also ineffective in promoting germination (data not shown).

Germination temperature had a significant effect on final germination rates, with the 32 / $22{ }^{\circ} \mathrm{C}$ regime giving the highest germination rate overall (Table 3 ). This temperature profile resulted in an average of nearly double the control of $22 / 22{ }^{\circ} \mathrm{C}$ and was especially advantageous after the shorter stratification periods. Average time to emergence decreased with increasing stratification period

Table 2. Effect of $\mathrm{H}_{2} \mathrm{O}_{2}$ and $\mathrm{GA}_{3}$ pretreatments and stratification period on muscadine seed viability.

\begin{tabular}{lc}
\hline $\begin{array}{l}\text { Seed stratification } \\
\text { period }^{\mathrm{z}}(\mathrm{d})\end{array}$ & Viable seed $^{\mathrm{y}}(\%)$ \\
\hline 0 & $88 \mathrm{c}$ \\
30 & $89 \mathrm{bc}$ \\
60 & $97 \mathrm{a}$ \\
90 & $95 \mathrm{ab}$ \\
\hline
\end{tabular}

Significance

Stratification period (SP) $\quad * * *$
$\mathrm{H}_{2} \mathrm{O}_{2} \quad$ NS $\mathrm{GA}_{3}$ NS $\mathrm{SP} \times \mathrm{H}_{2} \mathrm{O}_{2}$

$\mathrm{SP} \times \mathrm{GA}_{3}$ $\mathrm{H}_{2} \mathrm{O}_{2} \times \mathrm{GA}_{3}$ $\mathrm{SP} \times \mathrm{GA}_{3} \times \mathrm{H}_{2} \mathrm{O}_{2}$ NS NS

${ }^{2}$ Combined data across all $\mathrm{H}_{2} \mathrm{O}_{2}$ and $\mathrm{GA}_{3}$ pretreatments.

${ }^{y}$ Viable seed percentage is the number of germinated seed plus ungerminated seed, which stained as viable divided by the total number of seed tested. Means followed by same letter are not significantly different according to Fisher's least significant difference $(P \leq 0.001)$.

${ }_{\mathrm{Ns},}^{* * * *}$ Nonsignificant or significant at $P \leq 0.001$, respectively.

$\mathrm{H}_{2} \mathrm{O}_{2}=$ hydrogen peroxide; $\mathrm{GA}_{3}=$ gibberellic acid .

Table 1. Effect of $\mathrm{H}_{2} \mathrm{O}_{2}$ and $\mathrm{GA}_{3}$ pretreatments and stratification period on muscadine seed final germination percentage.

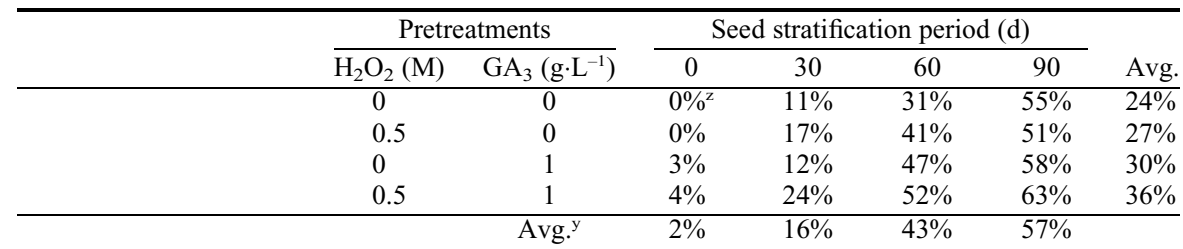

\begin{tabular}{lcc} 
Significance & df & $P$ value \\
\hline Stratification period (SP) & 3 & $* * *$ \\
$\mathrm{H}_{2} \mathrm{O}_{2}$ & 1 & $*$ \\
$\mathrm{GA}_{3}$ & 1 & $* * *$ \\
$\mathrm{SP} \times \mathrm{H}_{2} \mathrm{O}_{2}$ & 3 & NS \\
$\mathrm{SP} \times \mathrm{GA}_{3}$ & 3 & NS \\
$\mathrm{H}_{2} \mathrm{O}_{2} \times \mathrm{GA}_{3}$ & 1 & NS \\
$\mathrm{SP} \times \mathrm{GA}_{3} \times \mathrm{H}_{2} \mathrm{O}_{2}$ & 3 & NS
\end{tabular}

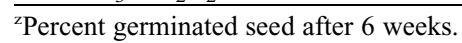

${ }^{y}$ Means followed by same letter are not significantly different according to Duncan's multiple range test $(P \leq 0.001)$.

${ }_{\mathrm{Ns}, * * * * *}$ Nonsignificant or significant at $P \leq 0.05$ or 0.001 , respectively.

$\mathrm{H}_{2} \mathrm{O}_{2}=$ hydrogen peroxide; $\mathrm{GA}_{3}=$ gibberellic acid. 
and increasing germination temperature (Table 4). Seedlings emerged $\approx 0.7$ weeks sooner at the $37 / 22^{\circ} \mathrm{C}$ temperature than at the $22 / 22{ }^{\circ} \mathrm{C}$ temperature. Interestingly, emer-

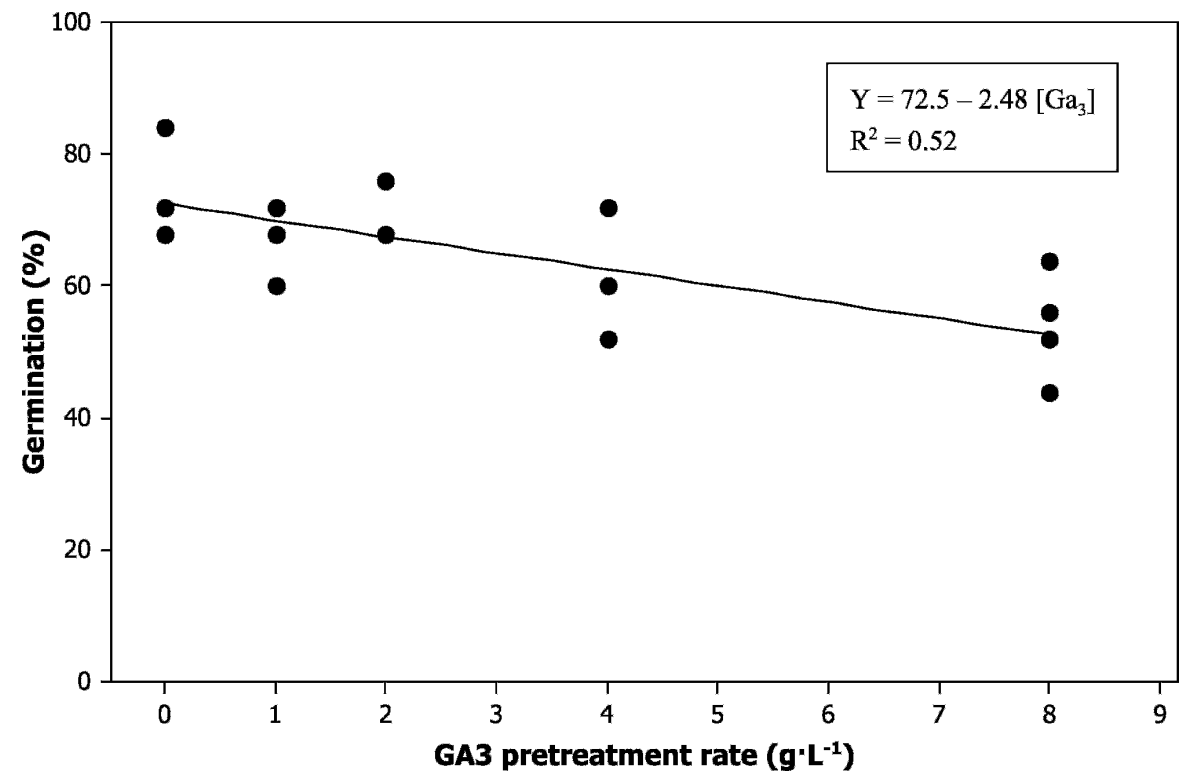

Fig. 1. Regression of percent germination of 'Fry' muscadine seed on rate of gibberellic acid $\left(\mathrm{GA}_{3}\right)$ pretreatment. For each replication, 25 seeds were soaked in $10 \mathrm{~mL}$ of the $\mathrm{GA}_{3}$ solution for $24 \mathrm{~h}$ and then stratified for $60 \mathrm{~d}$. Four replications of 25 seeds were conducted for each $\mathrm{GA}_{3}$ pretreatment rate. Final germination percentage was calculated after 5 weeks.

Table 3. Effects of germination temperature, stratification period, seed type on Fry muscadine seed germination percentage.

\begin{tabular}{lccccccc}
\hline Stratification period (d) & & 0 & 30 & 60 & 90 & 90 & \\
\hline Seed type & & \multicolumn{2}{c}{ Dry } & & Fresh & Avg. \\
Germination temp & $22 / 22{ }^{\circ} \mathrm{C}^{\mathrm{y}}$ & $0 \% 0^{\mathrm{x}}$ & $11 \%$ & $22 \%$ & $49 \%$ & $38 \%$ & $21 \%$ \\
& $27 / 22{ }^{\circ} \mathrm{C}$ & $2 \%$ & $7 \%$ & $28 \%$ & $53 \%$ & $50 \%$ & $23 \%$ \\
& $32 / 22{ }^{\circ} \mathrm{C}$ & $16 \%$ & $36 \%$ & $44 \%$ & $68 \%$ & $73 \%$ & $41 \%$ \\
& $37 / 22{ }^{\circ} \mathrm{C}$ & $7 \%$ & $23 \%$ & $47 \%$ & $36 \%$ & $46 \%$ & $28 \%$ \\
\hline & Avg. & $6 \%$ & $19 \%$ & $35 \%$ & $52 \%$ & $52 \%$ &
\end{tabular}

Significance

Stratification period (SP)

Germination temp (GT)

Seed type

$\mathrm{SP} \times \mathrm{GT}$

\begin{tabular}{cc} 
df & \\
\hline 3 & $* * *$ \\
3 & $* * *$ \\
1 & NS \\
9 & $* *$
\end{tabular}

${ }^{2}$ Dry seed was dried for several days before processing; fresh seed was never allowed to dry.

${ }^{\mathrm{y}} \mathrm{Temp} 1 /$ temp 2 . Seeds were placed in light at temperature 1 for $8 \mathrm{~h}$ and in darkness at temperature 2 for $16 \mathrm{~h}$. ${ }^{x}$ Final germination percentage after 8 weeks.

Ns, **,****Nonsignificant or significant at $P \leq 0.01$ or 0.001 , respectively.

Table 4. Effect of germination temperature, stratification period, and seed handling on rate of Fry muscadine seedling emergence.

\begin{tabular}{lcccccc}
\hline Stratification period $(\mathrm{d})$ & & 30 & 60 & 90 & 90 & \\
\hline Seed type $^{\mathrm{z}}$ & & & Dry & & Fresh & Avg. \\
Germination temp & $22 / 22^{\circ} \mathrm{C}^{\mathrm{y}}$ & $4.5^{\mathrm{x}}$ & 4.2 & 3.7 & 4.1 & 4.1 \\
& $27 / 22^{\circ} \mathrm{C}$ & 4.3 & 3.3 & 3.2 & 3.6 & 3.6 \\
& $32 / 22^{\circ} \mathrm{C}$ & 4.5 & 3.7 & 3.4 & 3.8 & 3.9 \\
& $37 / 22^{\circ} \mathrm{C}$ & 3.6 & 3.2 & 3.1 & 3.7 & 3.4 \\
\hline & $\mathrm{Avg}$. & 4.2 & 3.6 & 3.3 & 3.8
\end{tabular}

Significance

Stratification period (SP)

Germination temperature (GT)

Seed type

$\mathrm{SP} \times \mathrm{GT}$

$\begin{array}{cc}\text { df } & * * * \\ 3 & * * * \\ 3 & * * * \\ 1 & \text { NS } \\ 9 & \end{array}$

${ }^{\mathrm{z}}$ Dry seed was dried for several days before processing; fresh seed was never allowed to dry.

${ }^{y}$ Temp $1 /$ temp 2 . Seeds were placed in light at temperature 1 for $8 \mathrm{~h}$ and in darkness at temperature 2 for $16 \mathrm{~h}$. ${ }^{\mathrm{x}}$ Average week of seedling emergence.

Ns, ${ }^{* * *}$ Nonsignificant or significant at $P \leq 0.001$, respectively. the cooler temperature, only the most vigorous seed germinated. Drying of the seed had no effect on final seed germination percentage (Table 3), but did slow the rate of germination (Table 4).

\section{Discussion}

Muscadine grapes are native to the southern United States where winter temperatures commonly fluctuate from mild to cold. It is not surprising, therefore, that muscadine seeds have a relatively pernicious endodormancy that prevents them from germinating during brief warm periods in the winter. In addition, muscadine seed has a very thick seedcoat to protect the seed as it travels through the digestive tract of animal dispersers. As a result, muscadine seed germination can be slow and erratic. Once the seed germinates, however, growth is usually quite vigorous. In our breeding program, seed is typically planted in January so that seedlings can be transplanted in the field in March. This allows vines a maximum amount of time to grow in the first year, and a large percentage will flower the second year. This process is hampered in some crosses by delayed or poor germination, necessitating a better protocol to remove seed dormancy. Ideally, such a protocol would be relatively easy to apply to progenies of several thousand seed and would require a relatively short stratification period.

As a starting point, this experiment investigated the effects of the $\mathrm{GA}_{3}$ and $\mathrm{H}_{2} \mathrm{O}_{2}$ pretreatments recommended by Ellis et al. (1983) for Euvitis grape seed. $\mathrm{GA}_{3}$ is an exogenous growth regulator that promotes germination by stimulating the activation of food-mobilizing enzymes (Hartman and Kester, 1983). The mode of action of $\mathrm{H}_{2} \mathrm{O}_{2}$ in the promotion of germination is unclear but may involve the scarification of the seedcoat (Chien and Lin, 1994; Keeley and Fotteringham, 1998) or oxidation of germination inhibitors (Ogawa and Iwabuchi, 2001). Although both pretreatments promoted muscadine germination in Expt. 1, the benefits were marginal and did not substitute for longer stratification periods. In addition, even the best combination of seed treatments still left over $30 \%$ of the seed with unbroken dormancy as judged by the viability of ungerminated seed. This is in contrast to Ellis et al. (1983) in which these pretreatments resulted in the germination of virtually all viable seed.

Given the marginal efficacy of the previous pretreatments, Expt. 2 investigated a wider range of concentrations of $\mathrm{GA}_{3}$ and $\mathrm{H}_{2} \mathrm{O}_{2}$. Increasing the $\mathrm{H}_{2} \mathrm{O}_{2}$ concentration was ineffective in promoting germination, and increasing the $\mathrm{GA}_{3}$ concentration resulted in a decrease in germination. Concentrations of $\mathrm{GA}_{3}$ of $2 \mathrm{~g} \cdot \mathrm{L}^{-1}$ were also found by Ellis et al. (1983) to cause the death of a percentage of seed in some seed lots. The $\mathrm{H}_{2} \mathrm{O}_{2}$ pretreatment appears to be marginally valuable because it gave a significant benefit in the first experiment and, although not significant, was numerically better in the second 
experiment. The $1 \mathrm{~g} \cdot \mathrm{L}^{-1} \mathrm{GA}_{3}$ treatment may also be beneficial because it was favorable in the first experiment and only appeared to be inhibitory at the higher rates in the second experiment. Mechanically scarifying seeds by nicking the seedcoat did not improve germination, suggesting that dormancy is not controlled by the impermeability of the seedcoat. Leaching the seeds after stratification was also ineffective in reducing seed dormancy, also in contrast to what was found in Euvitis (ChiaWei and ShyiKuan, 2003; Ellis et al., 1983).

Germination temperatures have a strong influence on the germination of Euvitis seed. Ellis et al. (1983) found that an alternating temperature of $30 / 20^{\circ} \mathrm{C}$ resulted in increased germination over a single temperature of 20 or $30{ }^{\circ} \mathrm{C}$. Results from Expt. 3 indicate that muscadine seed germination is improved by providing at least a brief period of warmer temperatures. However, a single warm temperature was not tested, so it is not clear if a single warm temperature would provide the same benefit. We have previously noticed that muscadine seedling progenies planted later in the spring emerge sooner than those planted earlier in the year, and the results of Expt. 3 confirm the observation that warmer temperatures increase the speed of germination.
As a practical matter, the results of these experiments suggest that a $0.5 \mathrm{M} \mathrm{H}_{2} \mathrm{O}_{2}$ and a $1 \mathrm{~g} \cdot \mathrm{L}^{-1} \mathrm{GA}_{3}$ pretreatment are not likely to be harmful and will benefit muscadine seed germination in at least some instances. Seed should be stratified at least $90 \mathrm{~d}$ and germinated in an environment where daytime temperatures are allowed to reach $30^{\circ} \mathrm{C}$.

\section{Literature Cited}

ChiaWei, S. and O. ShyiKuan. 2003. Improving seed germination of 'Kyoho' grape by treatments of gibberellic acid, leaching, scarification, and stratification. J. Agr. Res. China 52: 14-22.

Chien, C. and T. Lin. 1994. Mechanism of hydrogen peroxide in improving the germination of Cinnamon camphora seed. Seed Sci. \& Technol. 22:231-236.

Einsett, J. and C. Pratt. 1975. Grapes, p. 130-135. In: Janick, J. and J.N. Moore (eds.). Advances in fruit breeding. Purdue Univ. Press, West Lafayette, IN.

Ellis, R.H., T.D. Hong, and E.H. Roberts. 1983. A note on the development of a practical procedure for promoting the germination of dormant seed of grape (Vitis spp.). Vitis 22:211-219.

Hartman, H.T. and D.E. Kester. 1983. Plant propagation principles and practices. 4th Ed. Prentice Hall, Englewood Cliffs, NJ.

Kachru, R.B., R.N. Singh, and I.S. Yadav. 1972. Physiological studies on dormancy in grape seeds (Vitis vinifera var. Black Muscat). Vitis 11:289-295.

Keeley, J.E. and C.J. Fotteringham. 1998. Smokeinduced seed germination in California chaparral. Ecology 79:2320-2336.

Nesbitt, W.B., J.B. Earp, and H.J. Kirk. 1976. After ripening and stratification of Vitis rotundifolia seed improves germination. HortScience 11:38 (abstr.).

Ogawa, K. and M. Iwabuchi. 2001. A mechanism for promoting the gercmination of Zinnia elegans seeds hydrogen peroxide. Plant and Cell Phys. 42:286-291.

Pal, R.N., R. Singh, V.K. Vij, and J.N. Sharma. 1976. Effect of gibberellins $\mathrm{GA}_{3}, \mathrm{GA}_{4 / 7}$, and $\mathrm{GA}_{13}$ on seed germination and subsequent seedling growth in Early Muscat grape (Vitis vinifera). Vitis 14:265-268.

Ramirez, O.C. 1968. Comparative embryogenesis of Erie, Concord, and Golden Muscat grape varieties as related to the germinability of seeds. Rutgers University. Brunswick, NJ. PhD Diss. Abstr. 29:1230-B.

Scott, D.H. and D.P. Ink. 1950. Grape seed germination experiments. Proc. Amer. Soc. Hort. Sci. 56:134-139.

Selim, H.H., F.A. Ibrahim, M.A. Fayek, S.A. ElDeen, and N.M. Gamal. 1981. Effect of different treatments on germination of Romi red grape seeds. Vitis 20:115-121.

Yeou-Der, K., R.J. Weaver, and R.M. Pool. 1967. Effect of low-temperature and growth regulators on germination of seeds of 'Tokay' grapes. J. Amer. Soc. Hort. Sci. 92:323-330. 